\title{
The case for diet: a safe and efficacious strategy for secondary stroke prevention
}

\author{
Jennifer L. Dearborn ${ }^{1}$ *, Victor C. Urrutia ${ }^{2}$ and Walter N. Kernan ${ }^{3}$ \\ 1 Department of Neurology, Yale University School of Medicine, New Haven, CT, USA \\ 2 Department of Neurology, Johns Hopkins University School of Medicine, Baltimore, MD, USA \\ ${ }^{3}$ Department of Internal Medicine, Yale University School of Medicine, New Haven, CT, USA
}

Edited by:

David S. Liebeskind, University of

California Los Angeles, USA

\section{Reviewed by:}

Shaida A. Andrabi, Johns Hopkins University School of Medicine, USA Edward Feldmann, Brown University, USA

\section{${ }^{*}$ Correspondence:}

Jennifer L. Dearborn, Yale University School of Medicine, LCI 1003, 15 York Street, New Haven, CT 06510, USA e-mail: jennifer.dearborn@yale.edu
Diet is strongly associated with risk for first stroke. In particular, observational and experimental research suggests that a Mediterranean-type diet may reduce risk for first ischemic stroke with an effect size comparable to statin therapy. These data for first ischemic stroke suggest that diet may also be associated with risk for recurrent stroke and that diet modification might represent an effective intervention for secondary prevention. However, research on dietary pattern after stroke is limited and direct experimental evidence for a therapeutic effect in secondary prevention does not exist. The uncertain state of science in this area is reflected in recent guidelines on secondary stroke prevention from the American Heart Association, in which the Mediterranean-type diet is listed with only a class Ila recommendation (level of evidence $\mathrm{C}$ ). To change guidelines and practice, research is needed, starting with efforts to better define current nutritional practices of stroke patients. Food frequency questionnaires and mobile applications for real-time recording of intake are available for this purpose. Dietary strategies for secondary stroke prevention are low risk, high potential, and warrant further evaluation.

Keywords: diet, secondary prevention stroke, dietary patterns, m-health

\section{INTRODUCTION}

Clinical research in nutrition for most of the past century examined the association between health and micronutrients (e.g., vitamins) or macronutrients (e.g., fat). In recent years, however, a growing body of research has also identified the importance of individual foods groups (e.g., fruit) on the incidence of cancer and cardiovascular disease including stroke (1). With substantial consistency, this work has demonstrated that higher consumption of fruits and vegetables, which are high in fiber, are associated with reduced risk for stroke (2-4).

Even more recently, investigators have turned their attention to dietary pattern and its effect on stroke risk, rather than particular food groups. Dietary patterns consumed along the Mediterranean, consisting of abundant fruits and vegetables, whole grains and low in processed foods, with a substantial polyunsaturated source of fat, such as olive oil, are consistently associated with reduced rates of stroke (5-10). The PREDIMED study, which was a multicenter randomized clinical trial comparing two Mediterraneanstyle diets with a low-fat diet, confirmed this association. Both Mediterranean-style diets reduced the risk of total stroke and ischemic stroke (11). These emerging data on diet and stroke risk raise the exciting possibility of a new, safe strategy for primary prevention of stroke. A great amount of work will be required, however, to confirm the promise of this strategy for secondary prevention and to develop suitable implementation methods for patients with established cerebrovascular disease. Below, we will summarize what we know about dietary patterns and stroke prevention, make some interim recommendations, and discuss how future work might help develop the potential for this therapeutic approach.

\section{DIET AND STROKE PREVENTION}

Numerous reviews and meta-analyses have summarized the evidence for food groups and risk of stroke, and below we highlight some important findings $(2,3,12-14)$. The majority of the evidence pertains to primary prevention of stroke in large cohort studies, and focuses on micronutrients, food groups, and dietary patterns. Two themes emerge: (1) increased fruit and vegetable consumption reduces stroke risk and (2) low-fat is not better for reducing rates of stroke, and may be a harmful risk reduction strategy.

Fruits and vegetables are protective against stroke, with one recent meta-analysis demonstrating that persons with the highest fruit and vegetable consumption were $21 \%$ less likely to have a stroke compared to those with the lowest consumption [relative risk reduction (RRR), 0.79 ; $95 \%$ confidence interval (CI), 0.71-0.84] (2). In the meta-analysis, the association was similar for fruit and vegetable consumption when considered separately. This is comparable to the effect size for statin use for prevention of stroke in high-risk patients, where statin use reduced all strokes by $18 \%$ (95\% CI, 13-23\%; $p<0.0001)$ (15). Nine large prospective cohorts with unique populations, such as the Nurses' Health Study, the Danish Diet, Cancer and Health Study, and the Framingham cohort among others add to the compelling evidence (16-20) that increasing fruit and vegetable consumption is associated with reduced burden of stroke. The INTERSTROKE study, designed to describe risk factors associations with the global burden of stroke, also demonstrated that fruit was associated with a lower risk of ischemic stroke (4). Across diverse populations with unique dietary patterns, mounting evidence is indicating that 
higher consumption of plant-based food-items is associated with reduced risk for stroke.

The evidence is not as consistent for other food groups (such as meat, dairy, and eggs) and incident stroke, but fish consumption seems to be beneficial. Overall, evidence suggests a modest protective effect of fish consumption and incident stroke $(4,21-$ 23), although some studies found no associations (24). This may depend on the way fish is eaten, as in many cultures fish is salted, which may negate its beneficial effects. One meta-analysis of 15 prospective studies reported a $6 \%$ reduction in stroke in by consuming an increment of three or more servings of fish per week (RRR, 0.94; 95\% CI, 0.89-0.99) (21). Japan, which has a much lower consumption of animal products and higher fish consumption than Western countries, has seen increasing consumption of meat, dairy, and eggs since the 1960s and during this time an associated reduction in cerebrovascular mortality. It is unclear if the increased consumption of animal products is truly protective, or if other dietary changes, such as a reduction in sodium, could account for this difference (25-27). In other cohorts, total meat consumption may be associated with a higher risk of ischemic stroke (12), however as meat consumption increases, it is likely that consumption of other beneficial food groups (such as fruits and vegetables) decreases.

There is increasing evidence that processed foods and meats may contribute to cardiovascular risk (28). Preservation of processed meats, such as ham, cold cuts, and bacon, occurs by smoking, curing, salting, or the addition of chemical preservatives. Although all studies do not share positive associations with stroke incidence and consumption of processed meats, a metaanalysis suggests an association exists $(28,29)$. The link between dairy foods, such as milk, cheese, and butter, and stroke is unclear, as no associations have been reproducibly demonstrated (30).

The association between dietary fat and risk for stroke is complex. Dietary fat is discussed in terms of: total fat, saturated, monounsaturated or polyunsaturated fat, or trans-fat. Saturated fats are found primarily in animal products, such as meat and dairy. Mono or polyunsaturated fats are found in vegetable oils and fish. Trans-fats are synthetic and found in margarine and other processed foods. Total fat, or other types of fat, were not associated with incident stroke in a 14-year follow-up study of US male healthcare professionals (31). Consistent with this observation, a randomized trial within the Women's Health Initiative demonstrated that a dietary modification to lower total fat also did not reduce stroke risk (32).

If a low-fat diet is not optimal for reduction of stroke risk, the type of fat may be important (22, 33-35). The U.S. Department of Agriculture released the food pyramid in 1992 to emphasize that "fat is bad," largely ignoring epidemiologic data about different types of fat. Nutrition science has moved beyond the pyramid, but its iconic message continues to influence public perceptions of "healthy eating" (36). One large meta-analysis suggested that saturated fat, previously recommended for lower intake to reduce cardiovascular disease incidence, was not associated with cardiovascular disease or stroke (37). These controversial results (38) have been supported by a large cohort, which showed a reduction in stroke risk with increased consumption of saturated fat in men (39). Evidence also suggests that increased consumption of certain types of polyunsaturated fats, such as long-chain omega-3 polyunsaturated fatty acids, may lower stroke risk (35) Trans-fats, on the other hand, may be associated with increased rates of stroke, at least in men (34). The effect of fat replacement (i.e., replacing saturated fats in the diet with polyunsaturated fats) has not been evaluated in stroke. The new initiative by the US Department of Agriculture, My Plate, has replaced the pyramid and shifts emphasis from lowering fat consumption to increasing relative consumption of fruits, vegetables, and whole grains (40). With existing data, it is difficult to make firm recommendations about fat consumption in stroke patients, and the best data will likely come from studies that incorporate whole dietary patterns (33).

Dietary patterns look at foods groups consumed together, rather that examining associations between individual foods and outcomes (41). Five large observational studies suggest that the Mediterranean-style diet: rich in fruits vegetables, low in red meat, with moderate alcohol, and use of olive oil or non-hydrogenated fats, may have the most potential as a dietary intervention to prevent stroke $(5-11,42)$. Prospective cohorts including the Nurses' Health Study, Northern Manhattan Study, and the European Investigation into Cancer, all demonstrate reduced stroke risk with this pattern $(7,9,10)$. A secondary prevention study in Lyon, France, also supported the potential of the Mediterranean diet to reduce recurrent cardiovascular events, however stroke was included as a part of a composite outcome (43). The dietary approaches to stop hypertension (DASH) diet, which similar to the Mediterranean diet, emphasized fruits, vegetables, as well as low intake of red meat and sweets, has also shown a benefit for stroke risk reduction (44). Another dietary pattern described in cohort studies is the Prudent diet, which also has a higher intake of fruits and vegetables, whole grains, legumes, and fish. Similarly, this dietary pattern has been associated with reduced risk of stroke (45).

There is almost no data on what stroke patients eat, either before or after their stroke. The majority of studies in diet and nutrition post-stroke have focused on measures of malnutrition or undernutrition (46-49), rather than diet quality, diet composition, or eating habits. In the absence of this information, it is difficult to identify potential opportunities for improvement. We do know that stroke may result in neurological complications (e.g., dysphagia, loss of motor control, and depression) that may increase risk for malnutrition. Aphasic patients may not be able to communicate when they are hungry or what they want to eat, and prolonged hospitalization may alter metabolic function and metabolic needs. Designing a nutritional intervention must take account of these complications for individual patients.

\section{IMPORTANCE OF DIET FOR REGIONAL DIFFERENCES IN STROKE RISK}

Variation in dietary pattern between geographic regions may be one explanation for geographic variation in stroke risk. The "Stroke Belt" in southeastern United States defines an 11-state region with particularly high rates of stroke and cardiovascular disease, including an area ranging from North Carolina to Louisiana $(50,51)$. The NINDS-funded REGARDS study is an observational study designed to understand why people in this part of the country are at a higher risk of stroke. A dietary pattern, known as the "Southern" pattern has been described in the REGARDS study; 
it is high in fried foods, organ and processed meat, and sugarsweetened beverages (52). This dietary pattern is associated with increased incidence of stroke in this region. The southern diet is an example of diet preferences (such as sweet tea) that may be similar within neighborhoods because of ethnic backgrounds, economic reasons, or be due to food choice and accessibility of restaurants and grocery stores (53-55). It is of no surprise that, along with diet, obesity, and chronic diseases including diabetes and cardiovascular disease cluster within neighborhoods, and are especially prevalent in minority communities (56-58). Increased rates of stroke are described in impoverished neighborhoods as compared with more affluent communities (59-62). Dietary patterns may be part of the causal pathway in "high-risk" communities with high rates of stroke $(5,6,52,63)$.

There is significant geographic variability in type of fats consumed. Asian countries such as China, Japan, and South Korea have the lowest per-capita consumption of saturated fats, while in many Latin American countries, consumption of more beneficial polyunsaturated fats may be low (64). Some Pacific island nations have high intakes of palm oil, which is known to be high in saturated fat, and therefore have low polyunsaturated fat consumption. Higher consumption of seafood, rich in omega-3 polyunsaturated fat, is present in the Mediterranean, Iceland, South Korea, Pacific Islands, and Japan, however is extremely low in many other parts of the world, including Sub-Saharan Africa and South America (65). The contribution of these differences in fat consumption to incident stroke is largely unstudied.

Improved population data is facilitating research on the association between diet and stroke risk in low, middle, and high-income countries (66). One must be cautious in interpreting this research, however, because of potential confounding by factors such as air pollution, smoking rates, and genetic risk. Greece, for example has higher stroke mortality than Sweden despite a diet that should afford more protection against vascular disease (66). With careful characterization of diet at a regional level, and rigorous examination of possible confounders, more accurate conclusions about the aspects of diet that explain regional differences can be understood. Given the lack of detailed dietary information in many regions (for example urban versus rural US populations), there is a need for an accurate, convenient method for quantifying diet for populations at risk of stroke. Technology, specifically mobile health applications, may play a role in defining the phenotype.

\section{METHODS FOR MEASURING DIETARY PATTERN}

There are three common methods to record a person's diet: a dietary record, 24-h diet recall and food frequency questionnaires (FFQs) (67). Dietary records document foods as they are consumed, usually for 3 or 4 days. They may be affected by error if respondents modify or systematically underreport food eaten, or if compliance is non-random. The 24-h diet recall is completed as a patient writes down foods that they have consumed in the past $24 \mathrm{~h}$. This method is simple to administer, and does not require an intensive time commitment. It may not be accurate, however, if the sampling interval is not representative of the respondent's typical diet.

Food frequency questionnaires are commonly used in large cohort studies and ask a participant to report how often he or she consumes food items over an average time frame, such as the past week (68). Several FFQs have been validated for use. These tools are simple to administer and semi-quantitative in that total daily intakes of food groups can be estimated (69-71). A typical FFQ includes 60-200 items, including simple foods, like apples or carrots, or complex foods specific to the region studies, such as grits or lasagna. However, this, too, is a rough estimate of an individual's diet pattern, and may be affected by personality characteristics that lead to over or under reporting. This is often the method of choice in cohort studies because of ease of administration, and reproducibility, but its validity is determining actual consumption is limited (72). Measurement error in the tool of choice, can lead to missed associations with chronic disease (73).

Food frequency questionnaire and 24-h recalls are commonly used to classify specific eating patterns using a priori diet scores. One example is the Mediterranean Diet Score, based on foods typically eaten in the Mediterranean region, which creates a numeric score of $0-9$, based on nine food group items, where a subject would get a point for each food group if they are above the median value of the sex-specific consumption for beneficial food-items (74). Diet scores have also been created for measuring adherence to US Government dietary recommendations (33), consumption of carbohydrates $(75,76)$, and adherence to the DASH diet (44, 77) (Table 1). The benefit of a diet score is that it may allow a hypothesis driven approach to study outcomes. For example, the Healthy Eating Index was created to study the nutrient needs and dietary guidelines of the US consumer, with the potential for the US Department of Agriculture to incorporate it into health promotion methods (78). This index incorporates a 10-component score of 5 food groups, 4 nutrients, and 1 measure of the variety of food intake. The DASH diet score allows a dietary intervention developed as a part of a randomized controlled trial (79) to be used in a prospective community-based cohort, by incorporating data from a FFQ.

Unlike a priori diet scores, which develop from hypotheses about food groupings, principal components analysis is a datadriven approach used to examine food consumed in individuals that are correlated. The goal is to break the food groups into a smaller amount of groupings of correlated components, called clusters, to describe the diet patterns with fewer variables (81). As each principal components analysis is specific to the cohort studied, the generalizability to other populations can be questioned. However, within each cohort, they can elucidate patterns of eating associated with disease outcomes that incorporate the total diet. Examples of dietary patterns described are a "Prudent" pattern (high in fruits and vegetables, "low in red meat") and a "Western" pattern, which is high in red meat, processed foods, and sweets (45). It is important to compare this approach to analyses across cohorts to determine if the associations of different patterns with stroke have similar food groupings. Table 1 shows the major studies that have examined dietary patterns with ischemic stroke as the outcome $(6,7,9,10,39,44,45,52,76,80)$.

Portion size is defined by the amount of food a person chooses to eat at a given time. Recommendations by groups such as the U.S. Department of Agriculture are based on serving size, which is a standard amount of food recommended for consumption. In epidemiologic and clinical studies, it is challenging to measure 
Table 1 | Summary of stroke studies including a priori and principal components analysis for defined dietary patterns

\begin{tabular}{|c|c|c|c|}
\hline Cohort & $N$ & Dietary patterns & Associations with stroke \\
\hline Male health professionals, & 38,615 & Alternate healthy eating index (AHEI) & Stroke grouped with all cardiovascular disease (CVD) \\
\hline Nurses (33) & 67,271 & Recommended food score (RFS) & $\begin{array}{l}\text { High AHEI score associated with reduced risk of CVD } \\
\text { RFS predicted risk of CVD in men but not women }\end{array}$ \\
\hline Europeans (6) & 47,021 & $\begin{array}{l}\text { Healthy eating index (HEI); dietary approaches to } \\
\text { stop hypertension (DASH); Greek Mediterranean } \\
\text { index; Italian Mediterranean index }\end{array}$ & $\begin{array}{l}\text { Three indices (not } \mathrm{HEI} \text { ) associated with lower risk of stroke, } \\
\text { with the greatest risk reduction for the Italian Mediterranean } \\
\text { index }\end{array}$ \\
\hline Europeans (75) & 44,099 & Glycemic index and glycemic load & High glycemic index associated with increasing risk of stroke \\
\hline Europeans (9) & 40,011 & Mediterranean diet & $\begin{array}{l}\text { Better adherence to Mediterranean diet inversely associated } \\
\text { with stroke }\end{array}$ \\
\hline $\begin{array}{l}\text { New York city } \\
\text { residents (10) }\end{array}$ & 3,298 & Mediterranean diet & $\begin{array}{l}\text { No association between Mediterranean diet and risk of } \\
\text { ischemic stroke }\end{array}$ \\
\hline Nurses (7) & 74,866 & Mediterranean diet & $\begin{array}{l}\text { Greater adherence to the Mediterranean diet associated } \\
\text { with a lower risk of stroke }\end{array}$ \\
\hline Nurses (44) & 88,517 & DASH & DASH score associated with lower risk of stroke \\
\hline Nurses (76) & 78,779 & Glycemic index and glycemic load & $\begin{array}{l}\text { Carbohydrate intake associated with increased risk of } \\
\text { hemorrhagic but not ischemic stroke }\end{array}$ \\
\hline Nurses (45) & 121,700 & Prudent and Western & $\begin{array}{l}\text { Western pattern associated with higher risk of stroke; } \\
\text { prudent pattern trended toward a lower risk of stroke }\end{array}$ \\
\hline $\begin{array}{l}\text { U.S., oversampled } \\
\text { Southeast residents (52) }\end{array}$ & 30,239 & $\begin{array}{l}\text { Convenience; Southern; plant-based; sweets/fats; } \\
\text { alcohol/salads }\end{array}$ & $\begin{array}{l}\text { Southern style diet may increase stroke risk; plant-based } \\
\text { diet may reduce stroke risk }\end{array}$ \\
\hline $\begin{array}{l}\text { Multi-ethnic U.S. } \\
\text { population (80) }\end{array}$ & 6,814 & $\begin{array}{l}\text { Fat and processed meat; vegetables and fish; } \\
\text { beans, tomatoes, and refined grains; whole grains } \\
\text { and fruit }\end{array}$ & $\begin{array}{l}\text { Stroke grouped with CVD; fat and processed meat } \\
\text { associated with higher risk of CVD; whole grains and fruit } \\
\text { associated with lower hazard CVD }\end{array}$ \\
\hline
\end{tabular}

portion size because of systemic bias in over or under reporting. This leads to errors in total energy calculations, which are shown to be underreported in nationwide surveys (82). Therefore systematic research on portion size and disease outcomes, such as stroke is lacking. We do know however, that for weight loss, which is associated with reduced incidence of cardiovascular disease, the total amount of calories seems to be more important than the composition of the macronutrients (i.e., proportion of carbohydrates, fats, and protein) (83).

\section{EMERGING MOBILE TECHNOLOGIES}

Mobile technology provides an opportunity to better measure dietary consumption because of several key factors: (1) it is widely available and commonly used for other purposes (namely mobile phones), (2) in modern society most always have a mobile phone at hand, which is an opportunity to record data at the moment of food consumption, and (3) mobile phones have the ability to wirelessly transmit data collected (84). These features are excellent for stroke research because they can improve the accuracy of dietary data collected and ensure that it is collected in a standardized format ready for analysis. The ubiquitous mobile phone would allow individuals in harder to reach or understudied/minority communities to participate in research so that the full phenotype of dietary patterns can be discovered.
The mobile health ( $\mathrm{m}$-health) revolution began in a response to these observations, and $\mathrm{m}$-health strategies have been employed in a variety of applications in the developing world and in harder to reach communities (85). One of the successes in m-health applications has been in diabetes education, in which patients are able to record food records and blood sugars, which can be transmitted to researchers and doctors (86). Many of the interventions invoke cell phone text messages, known as Short Message Service (SMS), to remind patients about blood sugar control, and show moderate efficacy in supporting patient's self-management (87). Other mobile applications seek to detect atrial fibrillation in asymptomatic patients in the community by a single lead EKG embedded in an iPhone (88). Dietary interventions are currently proposed using $\mathrm{m}$-health to improve fruit and vegetable consumption in young adults (89). Other than primary prevention of cardiovascular diseases or diabetes, data on m-health applications in stroke is growing in areas such as telemedicine and before hospital triage, but applications in diet and secondary prevention are lacking (90).

An exciting application that could have particular relevance to diet and stroke prevention involves mobile nutrition records that are recorded via photographs of foods being eaten $(91,92)$. Each photograph is set with a fiducial marker so that measurement of portion size can be accurate, and the photograph is compared with 




FIGURE 1 | Mobile health, diet, and potential clinical applications. Above is an example of how patients can use mobile health technology to record dietary intake to be interpreted in the clinic setting. Using smart technology, daily intake and portion size could be calculated for foods consumed. The computer algorithm could determine the overall meal quality, based on dietary recommendations, and the dietary pattern that the person adheres to. Patients could be counseled on his or her stroke risk attributable to diet, based on information from population-based studies. This information could lead to individualized diet recommendations for stroke prevention.

a database of foods for similarities so that portion size and foods can be identified. User interaction and confirmation of foods and portion sizes is still critical, but can often be done after the meal if the image is captured. This technology is still investigational and requires validation with other food recording methods, but is very promising because it allows for standardization and automatization of food portion sizes and calorie counts between subjects. This no longer relies on individuals to "estimate" portion sizes and total calories. It has the potential to be more "user-friendly" by allowing participants to take a picture, rather than search for foods consumed through cumbersome electronic food records (93, 94). Figure 1 shows a potential application of this technology in a patient population. It is clear that more rigorous validation of mobile health food records is needed in comparison with the FFQ and other techniques, but the benefits to the user of such methods are evident.

\section{FUTURE DIRECTIONS AND CONCLUSION}

Statin use has been widely incorporated into clinical recommendations and quality control measures in the care of patients with stroke, based on available evidence that demonstrates efficacy in secondary prevention. A healthy diet may have a similar effect size for secondary prevention but is hardly mentioned during hospital admissions and clinic follow-up visits for stroke patients. This may be because there is no direct research data to show that any specific diet is more effective than another in secondary stroke prevention. There is also a lack of support for nutritional counseling in many clinics and hospitals. Finally, even with adequate knowledge and support, patients have great difficulty adopting new dietary patterns. These three challenged are not insurmountable, but overcoming them will require research on nutritional epidemiology in stroke, comparative effectiveness of various diets, and implementation.

As a reasonable first step, better characterization of diet phenotype in stroke patients may reveal specific opportunities for improvement and suggest further research directions. If most stroke patients eat poorly, for example, then efforts to intervene might gain attention. If the research shows common adverse dietary practices in stroke patients within the same geographic region, then community-based interventions might gain attention. Only carefully designed survey research, furthermore, will identify barriers to optimal nutrition in stroke patients and provide the information that is needed to design and test effective implementation strategies.

\section{ACKNOWLEDGMENTS}

We would like to recognize Anthony Kwan who completed the illustration for this manuscript.

\section{REFERENCES}

1. Tracy SW. Something new under the sun? The Mediterranean diet and cardiovascular health. N Engl J Med (2013) 368(14):1274-6. doi:10.1056/NEJMp1302616

2. Hu D, Huang J, Wang Y, Zhang D, Qu Y. Fruits and vegetables consumption and risk of stroke: a meta-analysis of prospective cohort studies. Stroke (2014) 45(6):1613-9. doi:10.1161/STROKEAHA.114.004836

3. Threapleton DE, Greenwood DC, Evans CEL, Cleghorn CL, Nykjaer C, Woodhead C, et al. Dietary fiber intake and risk of first stroke: a systematic review and meta-analysis. Stroke (2013) 44(5):1360-8. doi:10.1161/STROKEAHA.111. 000151

4. O’Donnell MJ, Xavier D, Liu L, Zhang H, Chin SL, Rao-Melacini P, et al. Risk factors for ischaemic and intracerebral haemorrhagic stroke in 22 countries (the INTERSTROKE study): a case-control study. Lancet (2010) 376(9735):112-23. doi:10.1016/S0140-6736(10)60834-3

5. Psaltopoulou T, Sergentanis TN, Panagiotakos DB, Sergentanis IN, Kosti R, Scarmeas N. Mediterranean diet, stroke, cognitive impairment, and depression: a meta-analysis. Ann Neurol (2013) 74(4):580-91. doi:10.1002/ana.23944

6. Agnoli C, Krogh V, Grioni S, Sieri S, Palli D, Masala G, et al. A priori-defined dietary patterns are associated with reduced risk of stroke in a large Italian cohort. J Nutr (2011) 141(8):1552-8. doi:10.3945/jn.111.140061

7. Fung TT, Rexrode KM, Mantzoros CS, Manson JE, Willett WC, Hu FB. Mediterranean diet and incidence of and mortality from coronary heart disease and stroke in women. Circulation (2009) 119(8):1093-100. doi:10.1161/ CIRCULATIONAHA.108.816736

8. Scarmeas N, Luchsinger JA, Stern Y, Gu Y, He J, DeCarli C, et al. Mediterranean diet and magnetic resonance imaging-assessed cerebrovascular disease. Ann Neurol (2011) 69(2):257-68. doi:10.1002/ana.22317

9. Hoevenaar-Blom MP, Nooyens AC, Kromhout D, Spijkerman AM, Beulens JW, van der Schouw YT, et al. Mediterranean style diet and 12-year incidence of cardiovascular diseases: the EPIC-NL cohort study. PLoS One (2012) 7(9):e45458. doi:10.1371/journal.pone.0045458

10. Gardener H, Wright CB, Gu Y, Demmer RT, Boden-Albala B, Elkind MS, et al. Mediterranean-style diet and risk of ischemic stroke, myocardial infarction, and vascular death: the Northern Manhattan Study. Am J Clin Nutr (2011) 94(6):1458-64. doi:10.3945/ajcn.111.012799

11. Estruch R, Ros E, Salas-Salvado J, Covas MI, Corella D, Aros F, et al. Primary prevention of cardiovascular disease with a Mediterranean diet. $N$ Engl J Med (2013) 368(14):1279-90. doi:10.1056/NEJMoa1200303

12. Hankey GJ. Nutrition and the risk of stroke. Lancet Neurol (2012) 11(1):66-81. doi:10.1016/S1474-4422(11)70265-4

13. Medeiros F, Casanova Mde A, Fraulob JC, Trindade M. How can diet influence the risk of stroke? Int J Hypertens (2012) 2012:763507. doi:10.1155/2012/763507 
14. Sherzai A, Heim LT, Boothby C, Sherzai AD. Stroke, food groups, and dietary patterns: a systematic review. Nutr Rev (2012) 70(8):423-35. doi:10.1111/j.17534887.2012.00490.x

15. Amarenco P, Labreuche J. Lipid management in the prevention of stroke: review and updated meta-analysis of statins for stroke prevention. Lancet Neurol (2009) 8(5):453-63. doi:10.1016/S1474-4422(09)70058-4

16. Joshipura KJ, Ascherio A, Manson JE, Stampfer MJ, Rimm EB, Speizer FE, et al. Fruit and vegetable intake in relation to risk of ischemic stroke. JAMA (1999) 282(13):1233-9. doi:10.1001/jama.282.13.1233

17. Johnsen SP, Overvad K, Stripp C, Tjonneland A, Husted SE, Sorensen HT. Intake of fruit and vegetables and the risk of ischemic stroke in a cohort of Danish men and women. Am J Clin Nutr (2003) 78(1):57-64.

18. Mizrahi A, Knekt P, Montonen J, Laaksonen MA, Heliövaara M, Järvinen R. Plant foods and the risk of cerebrovascular diseases: a potential protection of fruit consumption. Br J Nutr (2009) 102(07):1075-83. doi:10.1017/S0007114509359097

19. Gillman MW, Cupples LA, Gagnon D, Posner BM, Ellison RC, Castelli WP, et al. Protective effect of fruits and vegetables on development of stroke in men. JAMA (1995) 273(14):1113-7. doi:10.1001/jama.1995.03520380049034

20. He FJ, Nowson CA, MacGregor GA. Fruit and vegetable consumption and stroke: meta-analysis of cohort studies. Lancet (2006) 367(9507):320-6. doi:10.1016/ S0140-6736(06)68731-X

21. Larsson SC, Orsini N. Fish consumption and the risk of stroke: a dose-response meta-analysis. Stroke (2011) 42(12):3621-3. doi:10.1161/STROKEAHA.111. 630319

22. He K, Rimm EB, Merchant A, Rosner BA, Stampfer MJ, Willett WC, et al. Fish consumption and risk of stroke in men. JAMA (2002) 288(24):3130-6. doi:10.1001/jama.288.24.3130

23. Xun P, Qin B, Song Y, Nakamura Y, Kurth T, Yaemsiri S, et al. Fish consumption and risk of stroke and its subtypes: accumulative evidence from a metaanalysis of prospective cohort studies. Eur J Clin Nutr (2012) 66(11):1199-207. doi:10.1038/ejcn.2012.133

24. Myint PK, Welch AA, Bingham SA, Luben RN, Wareham NJ, Day NE, et al. Habitual fish consumption and risk of incident stroke: the European Prospective Investigation into Cancer (EPIC)-Norfolk prospective population study. Public Health Nutr (2006) 9(07):882-8. doi:10.1017/PHN2006942

25. Kinjo Y, Beral V, Akiba S, Key T, Mizuno S, Appleby P, et al. Possible protective effect of milk, meat and fish for cerebrovascular disease mortality in Japan. J Epidemiol (1999) 9(4):268-74. doi:10.2188/jea.9.268

26. Sauvaget C, Nagano J, Hayashi M, Yamada M. Animal protein, animal fat, and cholesterol intakes and risk of cerebral infarction mortality in the adult health study. Stroke (2004) 35(7):1531-7. doi:10.1161/01.STR.0000130426.52064.09

27. Sauvaget C, Nagano J, Allen N, Grant EJ, Beral V. Intake of animal products and stroke mortality in the Hiroshima/Nagasaki life span study. Int J Epidemiol (2003) 32(4):536-43. doi:10.1093/ije/dyg151

28. Micha R, Wallace SK, Mozaffarian D. Red and processed meat consumption and risk of incident coronary heart disease, stroke, and diabetes mellitus: a systematic review and meta-analysis. Circulation (2010) 121(21):2271-83. doi:10.1161/CIRCULATIONAHA.109.924977

29. Kaluza J, Wolk A, Larsson SC. Red meat consumption and risk of stroke: a meta-analysis of prospective studies. Stroke (2012) 43(10):2556-60. doi:10. 1161/STROKEAHA.112.663286

30. Soedamah-Muthu SS, Ding EL, Al-Delaimy WK, Hu FB, Engberink MF, Willett WC, et al. Milk and dairy consumption and incidence of cardiovascular diseases and all-cause mortality: dose-response meta-analysis of prospective cohort studies. Am J Clin Nutr (2011) 93(1):158-71. doi:10.3945/ajcn.2010.29866

31. He K, Merchant A, Rimm EB, Rosner BA, Stampfer MJ, Willett WC, et al. Dietary fat intake and risk of stroke in male US healthcare professionals: 14 year prospective cohort study. BMJ (2003) 327(7418):777-82. doi:10.1136/bmj.327.7418.777

32. Howard BV, Van Horn L, Hsia J, Manson JE, Stefanick ML, Wassertheil-Smoller $\mathrm{S}$, et al. Low-fat dietary pattern and risk of cardiovascular disease: the women's health initiative randomized controlled dietary modification trial. JAMA (2006) 295(6):655-66. doi:10.1001/jama.295.1.39

33. McCullough ML, Feskanich D, Stampfer MJ, Giovannucci EL, Rimm EB, Hu FB, et al. Diet quality and major chronic disease risk in men and women: moving toward improved dietary guidance. Am J Clin Nutr (2002) 76(6):1261-71.

34. Kiage JN, Merrill PD, Judd SE, He K, Lipworth L, Cushman M, et al. Intake of trans fat and incidence of stroke in the reasons for geographic and racial differences in stroke (REGARDS) cohort. Am J Clin Nutr (2014) 99(5):1071-6. doi:10.3945/ajen.113.075713
35. Larsson SC, Virtamo J, Wolk A. Dietary fats and dietary cholesterol and risk of stroke in women. Atherosclerosis (2012) 221(1):282-6. doi:10.1016/j. atherosclerosis.2011.12.043

36. Willett WC, Stampfer MJ. Rebuilding the food pyramid. Sci Am (2003) 288(1):64-71. doi:10.1038/scientificamerican0103-64

37. Siri-Tarino PW, Sun Q, Hu FB, Krauss RM. Meta-analysis of prospective cohort studies evaluating the association of saturated fat with cardiovascular disease. Am J Clin Nutr (2010) 91(3):535-46. doi:10.3945/ajcn.2009.27725

38. Katan MB, Brouwer IA, Clarke R, Geleijnse JM, Mensink RP. Saturated fat and heart disease. Am J Clin Nutr (2010) 92(2):459-60. doi:10.3945/ajcn.2010. 29692

39. Gillman MW, Cupples LA, Millen BE, Ellison RC, Wolf PA. Inverse association of dietary fat with development of ischemic stroke in men. JAMA (1997) 278(24):2145-50. doi:10.1001/jama.278.24.2145

40. Agriculture USDo. USDA's My Plate. Available from: http://www.choosemy plate.gov

41. Tucker KL. Dietary patterns, approaches, and multicultural perspective. Appl Physiol Nutr Metab (2010) 35(2):211-8. doi:10.1139/H10-010

42. Sofi F, Abbate R, Gensini GF, Casini A. Accruing evidence on benefits of adherence to the Mediterranean diet on health: an updated systematic review and meta-analysis. Am J Clin Nutr (2010) 92(5):1189-96. doi:10.3945/ajcn.2010. 29673

43. de Lorgeril M, Salen P, Martin J-L, Monjaud I, Delaye J, Mamelle N. Mediterranean diet, traditional risk factors, and the rate of cardiovascular complications after myocardial infarction: final report of the lyon diet heart study. Circulation (1999) 99(6):779-85. doi:10.1161/01.CIR.99.6.779

44. Fung TT, Chiuve SE, McCullough ML, Rexrode KM, Logroscino G, Hu FB. Adherence to a DASH-style diet and risk of coronary heart disease and stroke in women. Arch Intern Med (2008) 168(7):713-20. doi:10.1001/archinte. 168.7.713

45. Fung TT, Stampfer MJ, Manson JE, Rexrode KM, Willett WC, Hu FB. Prospective study of major dietary patterns and stroke risk in women. Stroke (2004) 35(9):2014-9. doi:10.1161/01.STR.0000135762.89154.92

46. Axelsson K, Asplund K, Norberg A, Alafuzoff I. Nutritional status in patients with acute stroke. Acta Med Scand (1988) 224(3):217-24. doi:10.1111/j.09546820.1988.tb19364.x

47. Gariballa SE, Parker SG, Taub N, Castleden M. Nutritional status of hospitalized acute stroke patients. Br J Nutr (1998) 79(6):481-7. doi:10.1079/BJN19980085

48. Dávalos A, Ricart W, Gonzalez-Huix F, Soler S, Marrugat J, Molins A, et al. Effect of malnutrition after acute stroke on clinical outcome. Stroke (1996) 27(6):1028-32. doi:10.1161/01.STR.27.6.1028

49. Yoo SH, Kim JS, Kwon SU, Yun SC, Koh JY, Kang DW. Undernutrition as a predictor of poor clinical outcomes in acute ischemic stroke patients. Arch Neurol (2008) 65(1):39-43. doi:10.1001/archneurol.2007.12

50. Gillum RF, Kwagyan J, Obisesan TO. Ethnic and geographic variation in stroke mortality trends. Stroke (2011) 42(11):3294-6. doi:10.1161/STROKEAHA.111. 625343

51. Liao Y, Greenlund KJ, Croft JB, Keenan NL, Giles WH. Factors explaining excess stroke prevalence in the US stroke belt. Stroke (2009) 40(10):3336-41. doi:10.1161/STROKEAHA.109.561688

52. Judd SE, Gutierrez OM, Newby PK, Howard G, Howard VJ, Locher JL, et al. Dietary patterns are associated with incident stroke and contribute to excess risk of stroke in black Americans. Stroke (2013) 44(12):3305-11. doi:10.1161/ STROKEAHA.113.002636

53. Aggarwal A, Monsivais P, Drewnowski A. Nutrient intakes linked to better health outcomes are associated with higher diet costs in the US. PLoS One (2012) 7(5):e37533. doi:10.1371/journal.pone.0037533

54. Drewnowski A. Obesity, diets, and social inequalities. Nutr Rev (2009) 67(Suppl 1):S36-9. doi:10.1111/j.1753-4887.2009.00157.x

55. Block JP, Scribner RA, DeSalvo KB. Fast food, race/ethnicity, and income: a geographic analysis. Am J Prev Med (2004) 27(3):211-7. doi:10.1016/S07493797(04)00139-4

56. Flegal KM, Carroll MD, Kit BK, Ogden CL. Prevalence of obesity and trends in the distribution of body mass index among US adults, 1999-2010. JAMA (2012) 307(5):491-7. doi:10.1001/jama.2012.39

57. Ball K, Crawford D. Socio-economic factors in obesity: a case of slim chance in a fat world? Asia Pac J Clin Nutr (2006) 15(Suppl):15-20.

58. Isaacs SL, Schroeder SA. Class - the ignored determinant of the nation's health. N Engl J Med (2004) 351(11):1137-42. doi:10.1056/NEJMsb040329 
59. Brown AF, Liang LJ, Vassar SD, Merkin SS, Longstreth WT Jr, Ovbiagele B, et al. Neighborhood socioeconomic disadvantage and mortality after stroke. Neurology (2013) 80(6):520-7. doi:10.1212/WNL.0b013e31828154ae

60. Aslanyan S, Weir CJ, Lees KR, Reid JL, McInnes GT. Effect of area-based deprivation on the severity, subtype, and outcome of ischemic stroke. Stroke (2003) 34(11):2623-8. doi:10.1161/01.STR.0000097610.12803.D7

61. Lisabeth LD, Diez Roux AV, Escobar JD, Smith MA, Morgenstern LB. Neighborhood environment and risk of ischemic stroke: the brain attack surveillance in corpus christi (BASIC) project. Am J Epidemiol (2007) 165(3):279-87. doi:10.1093/aje/kwk005

62. Hunt BR, Deot D, Whitman S. Stroke mortality rates vary in local communities in a metropolitan area: racial and spatial disparities and correlates. Stroke (2014) 45(7):2059-65. doi:10.1161/STROKEAHA.114.005431

63. Morgenstern LB, Escobar JD, Sánchez BN, Hughes R, Zuniga BG, Garcia N, et al. Fast food and neighborhood stroke risk. Ann Neurol (2009) 66(2):165-70. doi:10.1002/ana.21726

64. Nettleton JA, Villalpando S, Cassani RSL, Elmadfa I. Health significance of fat quality in the diet. Ann Nutr Metab (2013) 63(1-2):96-102. doi:10.1159/ 000353207

65. Micha R, Khatibzadeh S, Shi P, Fahimi S, Lim S, Andrews KG, et al. Global, regional, and national consumption levels of dietary fats and oils in 1990 and 2010: a systematic analysis including 266 country-specific nutrition surveys. BMJ (2014) 348:g2272. doi:10.1136/bmj.g2272

66. Feigin VL, Forouzanfar MH, Krishnamurthi R, Mensah GA, Connor M, Bennett DA, et al. Global and regional burden of stroke during 1990-2010: findings from the global burden of disease study 2010. Lancet (2014) 383(9913):245-54. doi:10.1016/S0140-6736(13)61953-4

67. Thompson FE, Byers T. Dietary assessment resource manual. J Nutr (1994) 124(11 Suppl):2245S-317S.

68. Stefanik PA, Trulson MF. Determining the frequency intakes of foods in large group studies. Am J Clin Nutr (1962) 11(5):335-43.

69. Subar AF, Thompson FE, Kipnis V, Midthune D, Hurwitz P, McNutt S, et al. Comparative validation of the block, Willett, and national cancer institute food frequency questionnaires: the eating at America's table study. Am J Epidemiol (2001) 154(12):1089-99. doi:10.1093/aje/154.12.1089

70. Willett WC, Sampson L, Stampfer MJ, Rosner B, Bain C, Witschi J, et al. Reproducibility and validity of a semiquantitative food frequency questionnaire. Am J Epidemiol (1985) 122(1):51-65.

71. Block G, Woods M, Potosky A, Clifford C. Validation of a self-administered diet history questionnaire using multiple diet records. J Clin Epidemiol (1990) 43(12):1327-35. doi:10.1016/0895-4356(90)90099-B

72. Byers T. Food frequency dietary assessment: how bad is good enough? Am J Epidemiol (2001) 154(12):1087-8. doi:10.1093/aje/154.12.1087

73. Potter JD. Vegetables, fruit, and cancer. Lancet (2005) 366(9485):527-30. doi:10.1016/S0140-6736(05)67077-8

74. Trichopoulou A, Orfanos P, Norat T, Bueno-de-Mesquita B, Ocke MC, Peeters $\mathrm{PH}$, et al. Modified Mediterranean diet and survival: EPIC-elderly prospective cohort study. BMJ (2005) 330(7498):991. doi:10.1136/bmj.330.7503.1329-b

75. Sieri S, Brighenti F, Agnoli C, Grioni S, Masala G, Bendinelli B, et al. Dietary glycemic load and glycemic index and risk of cerebrovascular disease in the EPICOR cohort. PLoS One (2013) 8(5):e62625. doi:10.1371/journal.pone. 0062625

76. Oh K, Hu FB, Cho E, Rexrode KM, Stampfer MJ, Manson JE, et al. Carbohydrate intake, glycemic index, glycemic load, and dietary fiber in relation to risk of stroke in women. Am J Epidemiol (2005) 161(2):161-9. doi:10.1093/aje/ kwi026

77. Appel LJ, Moore TJ, Obarzanek E, Vollmer WM, Svetkey LP, Sacks FM, et al. A clinical trial of the effects of dietary patterns on blood pressure. N Engl J Med (1997) 336(16):1117-24. doi:10.1056/NEJM199704173361601

78. Kennedy ET, Ohls J, Carlson S, Fleming K. The healthy eating index: design and applications. J Am Diet Assoc (1995) 95(10):1103-8. doi:10.1016/S00028223(95)00300-2

79. Sacks FM, Svetkey LP, Vollmer WM, Appel LJ, Bray GA, Harsha D, et al. Effects on blood pressure of reduced dietary sodium and the dietary approaches to stop hypertension (DASH) diet. N Engl J Med (2001) 344(1):3-10. doi:10.1056/ NEJM200101043440101

80. Nettleton JA, Polak JF, Tracy R, Burke GL, Jacobs DR. Dietary patterns and incident cardiovascular disease in the multi-ethnic study of atherosclerosis. Am J Clin Nutr (2009) 90(3):647-54. doi:10.3945/ajcn.2009.27597
81. Newby PK, Katherine LT. Empirically derived eating patterns using factor or cluster analysis: a review. Nutr Rev (2004) 62(5):177-203. doi:10.1111/j.17534887.2004.tb00040.x

82. Institute of Medicine of the National Academies, Food and Nutrition Board. A report of the panel on macronutrients, subcommittees on upper reference levels of nutrients and interpretation and uses of dietary reference intakes, and the standing committee on the scientific evaluation of dietary reference intakes. Dietary Reference Intakes for Energy, Carbohydrate, Fiber, Fat, Fatty Acids, Cholesterol, Protein, and Amino Acids (Macronutrients). Washington, DC: The National Academies Press (2005). p. 1357. Available from: http://www.nap.edu/openbook.php?isbn $=0309085373$

83. Dietary Guidelines for Americans. Washington, DC: U.S. Department of Agriculture and U.S. Department of Health and Human Services (2010). Available from: http://www.health.gov/dietaryguidelines/

84. Maddison R, Whittaker R, Stewart R, Kerr A, Jiang Y, Kira G, et al. HEART: heart exercise and remote technologies: a randomized controlled trial study protocol. BMC Cardiovasc Disord (2011) 11:26. doi:10.1186/1471-2261-11-26

85. Kaplan WA. Can the ubiquitous power of mobile phones be used to improve health outcomes in developing countries? Global Health (2006) 2:9. doi:10.1186/ 1744-8603-2-9

86. Quinn CC, Shardell MD, Terrin ML, Barr EA, Ballew SH, Gruber-Baldini AL. Cluster-randomized trial of a mobile phone personalized behavioral intervention for blood glucose control. Diabetes Care (2011) 34(9):1934-42. doi:10.2337/dc11-0366

87. de Jongh T, Gurol-Urganci I, Vodopivec-Jamsek V, Car J, Atun R. Mobile phone messaging for facilitating self-management of long-term illnesses. Cochrane Database Syst Rev (2012) 12:Cd007459. doi:10.1002/14651858.CD007459.pub2

88. Lau JK, Lowres N, Neubeck L, Brieger DB, Sy RW, Galloway CD, et al. iPhone ECG application for community screening to detect silent atrial fibrillation: a novel technology to prevent stroke. Int J Cardiol (2013) 165(1):193-4. doi:10.1016/j.ijcard.2013.01.220

89. Kerr DA, Pollard CM, Howat P, Delp EJ, Pickering M, Kerr KR, et al. Connecting health and technology (CHAT): protocol of a randomized controlled trial to improve nutrition behaviours using mobile devices and tailored text messaging in young adults. BMC Public Health (2012) 12:477. doi:10.1186/1471-2458-12-477

90. Nam HS, Park E, Heo JH. Facilitating stroke management using modern information technology. J Stroke (2013) 15(3):135-43. doi:10.5853/jos.2013.15.3.135

91. Six BL, Schap TE, Zhu FM, Mariappan A, Bosch M, Delp EJ, et al. Evidencebased development of a mobile telephone food record. J Am Diet Assoc (2010) 110(1):74-9. doi:10.1016/j.jada.2009.10.010

92. Zhu F, Bosch M, Woo I, Kim S, Boushey CJ, Ebert DS, et al. The use of mobile devices in aiding dietary assessment and evaluation. IEEE J Sel Top Signal Process (2010) 4(4):756-66. doi:10.1109/JSTSP.2010.2051471

93. Boushey CJ, Kerr DA, Wright J, Lutes KD, Ebert DS, Delp EJ. Use of technology in children's dietary assessment. Eur J Clin Nutr (2008) 63(S1):S50-7. doi:10.1038/ejen.2008.65

94. Arab L, Estrin D, Kim DH, Burke J, Goldman J. Feasibility testing of an automated image-capture method to aid dietary recall. Eur J Clin Nutr (2011) 65(10):1156-62. doi:10.1038/ejcn.2011.75

Conflict of Interest Statement: The Review Editor Shaida A. Andrabi declares that, despite being affiliated to the same institution as author Victor C. Urrutia, the review process was handled objectively and no conflict of interest exists. The authors declare that the research was conducted in the absence of any commercial or financial relationships that could be construed as a potential conflict of interest.

Received: 09 October 2014; accepted: 03 January 2015; published online: 02 February 2015.

Citation: Dearborn JL, Urrutia VC and Kernan WN (2015) The case for diet: a safe and efficacious strategy for secondary stroke prevention. Front. Neurol. 6:1. doi: 10.3389/fneur.2015.00001

This article was submitted to Stroke, a section of the journal Frontiers in Neurology. Copyright (C) 2015 Dearborn, Urrutia and Kernan. This is an open-access article distributed under the terms of the Creative Commons Attribution License (CC BY). The use, distribution or reproduction in other forums is permitted, provided the original author(s) or licensor are credited and that the original publication in this journal is cited, in accordance with accepted academic practice. No use, distribution or reproduction is permitted which does not comply with these terms. 